\title{
AS INVENÇÕES E REINVENÇÕES DA VIRILIDADE
}

\author{
VIGARELLO, Georges. (Org.). História da virilidade: A invenção da virilidade, \\ da antiguidade às luzes. Petrópolis, RJ: Vozes, 2013. 614 páginas.
}

O livro resenhado é o primeiro volume de uma coletânea de três. Conduzida sob a direção de Alain Corbain, Jean-Jacques Courtine e Georges Vigarello, a coletânea pretende traçar uma genealogia da virilidade desde a antiguidade até a contemporaneidade. Esta resenha limita-se ao primeiro volume, organizado pelo historiador francês Georges Vigarello, conhecido por seus trabalhos referentes à história do corpo, da higiene e da saúde.

O volume se desdobra em vários capítulos, nos quais pesquisadoras/es buscam historiar a invenção da virilidade, o que hoje, nos estudos de gênero, conhecemos mais notadamente como masculinidade/s. Escrito em uma linguagem simples e envolvente, as pesquisas mostram que a construção do macho viril remonta à Grécia Antiga. Virilidade é uma característica masculina, do homem, e somente ele a possui. Na Grécia Antiga, trata-se de uma qualidade específica dos homens. Segundo Vigarello, a construção do ser humano masculino nessa época obedecia a uma construção educativa que em muito o distanciava da que se oferecia à mulher. A ele se destinavam e reservavam a eloquência, a política e o espaço da sociabilidade.

Essa virilidade aprendida tinha como referência o homem mais velho ou aquele que a sociedade assim respeitava. O jovem rapaz que precisava passar pela iniciação tinha como exemplo um homem mais velho que, por sua vez, devia ser conhecido por toda a comunidade. Este rito, questionável em nossa sociedade atual, na Grécia Antiga constituía o primeiro requisito da educação; só em seguida o respeito à família. O jovem rapaz somente poderia ter uma boa educação a partir dos aprendizados com o seu mestre. Locais onde a cópula entre homens era uma ação a ser realizada para poder aprender e reproduzir posteriormente, seja como mestre de futuros homens viris, seja como esposo.
Portanto, na Grécia Antiga, o homem que não convivesse com um mestre, a quem todos e todas na aldeia conhecessem, e com ele aprendesse, não seria um bom exemplo. Afeminados eram os homens que tinham seu corpo todo depilado, conhecidos como os 'estocados', ou simplesmente os 'afeminados', já que os homens viris eram os que possuíam pelos ou o 'rabo preto'. Logo, não poderia ser desejado pelas mulheres e seria desprezado pelos homens e sobre ele incidiria a suspeita de 'invertido'.

Nascer homem, na Grécia Antiga, era uma dádiva dos deuses; porém, tornar-se viril era penoso para o jovem grego cujos ritos de iniciação, inclusive sexuais, com o mestre começavam cedo. Isto explica por que a pederastia era algo comum, e, como relatado, era incentivada entre os seus pares como sinônimo de construção do homem viril. Diferentemente de Roma Antiga, a passagem da infância para a vida adulta do homem Grego era acompanhada por todos os homens da comunidade, principalmente os mais velhos para a reprodução do modelo viril. Esses ritos coletivos eram construções sociais que marcavam uma virilidade reconhecida e garantia a passagem da infância à idade adulta. Para o que denominamos hoje de pedofilia, na época grega, era educação. $O$ rapaz que não encontrasse um amante, seria desonrado e com algum defeito na educação.

É na Roma Antiga que o conceito de virilidade, ou virilitas, tem significado e sentido alterados. Em ambas as sociedades, porém, era construída sobre três grandes pilares: religião, família e comunidade. Na Roma Antiga, os rituais para um homem se tornar viril eram um tanto diferentes dos praticados pelos gregos. Segundo Thuillier, um jovem romano somente se tornaria vir quando tivesse tido relação com uma mulher, não bastando que a tivesse

\section{Assis Felipe Menin}

Mestre em História do Tempo Presente pela Universidade do Estado de Santa Catarina.

E-mail: a.f.menin@gmail.com 
mantido com garotos ou homens. Nesse sentido, a mulher romana exercia um certo protagonismo, pois somente ela poderia tornar Homem um homem. Diferentemente da Grécia, após o triunfo do cristianismo, romano respeitado era o que possuía apenas uma mulher; todavia, como no Grécia Antiga, ele não poderia ser o 'estocado', mas o 'estocador'. O homem romano deveria 'manter' a pose, a virilidade; mesmo deitando-se com outros homens, o estigmatizado era o 'estocado', e, mais notadamente, o 'efeminado'.

Na Roma Antiga, corpo bronzeado era sinônimo de virilidade; logo, o homem que não o fosse, teria a sua virilidade questionada, já que a cor pálida era típica da mulher. Além destas qualidades, homem romano era o que possuía um belo corpo - atlético, guerreiro e barbado -, pois a barba era sinônimo de que agora o jovem era um homem viril. Não de beleza formosa, sinônimo de feminilidade, mas de beleza máscula, pela qual era bonito ser viril. Prezava-se o culto à virilidade, o que constituía uma das diferenças entre a beleza feminina e a masculina, preservado, porém, o predomínio do masculino sobre o feminino, sinônimo de poder, principalmente quanto a participação da vida pública/política e o domínio da família por parte da mulher.

Poderíamos dizer que todo homem romano e grego era bissexual. Admitiam em comum, gregos e romanos, que a virilidade fosse apreendida com o outro e com os exemplos, mesmo que para isso fosse necessário apreender com outro homem.

A virilidade foi se transformando e diferenciando conforme as regiões, os povos e a religião.

Os bárbaros, assim conhecidos pelos romanos, tinham a virilidade bastante ligada ao exército, ao homem guerreiro. Se para o romano os pelos indicavam incivilidade, entre os bárbaros, cabelos compridos e homem peludo indicavam virilidade. $\mathrm{O}$ homem bárbaro, diferente do romano, era casto, pois ceder às tentações femininas era sinônimo de feminilidade, de fraqueza. Pior que o homem afeminado, era o que se dedicava às futilidades femininas.

Já os medievais tinham algo em comum com os bárbaros; eram castos. A castidade era sinônimo de virilidade, de força e virtude. Para um homem, perder a vida em uma batalha sangrenta era sinônimo de virilidade, mas o sangue em uma relação sexual, para o medieval, era sinônimo de feminilidade, pois quem deve perder o sangue é a mulher.

Vigarello mostra que delicadeza e virilidade caminham juntas na modernidade, com o homem absoluto. Na modernidade, é inventada a delicadeza, sendo considerada virtude também masculina. Essa virilidade delicada tem como principais representantes os reis. A riqueza, os perfumes, as luvas com anéis e os cabelos frisados inserem novos modelos de virilidade. Os reis dos séc. XVI e XVII, em suas pinturas, são um exemplo da nova invenção da virilidade, da que distinguiria a virilidade nobre da virilidade vulgar. Distinguiria o delicado do rude.

O leitor certamente constatará que a virilidade é marcada por diferenças no tempo e no espaço e, claro, de classe e posição social. Além desses fatores, os textos evidenciam haver outro componente na invenção da virilidade, o falo. $\mathrm{O}$ falo é objeto do livro e está presente em todos os capítulos. Como diz Kristzman (2013: 219), o pênis tem uma significação simbólica, que é o phallus, é com a simbologia viril deste órgão que os autores exploram o poder do macho.

Para corroborar suas teorias, os pesquisadores apresentam pinturas de reis da época da monarquia absolutista, nos quais a virilidade é muito representada na braguilha, pelo destaque que lhe dão. As pinturas da realeza demonstram que os pintores contratados enalteciam esses 'homens mais homens' a partir do desenho do órgão viril em suas pinturas, com uma braguilha avantajada, pois o falo representa o poder simbólico de dominação.

$\mathrm{Na}$ Renascença, as pinturas e suas representações são mais um fator psicológico da construção de um homem viril imaginário. E novamente, mesmo incorrendo num anacronismo histórico, não se pode deixar de pensar que a performatividade de gênero apresentada por Butler (2003) em Problemas de Gênero estava presente nas representações e no cotidiano do homem da antiguidade a performance de gênero -, presente em símbolos, signos e outros meios discursivos de dominação masculina. Butler (2003) escreve sobre a imitação performática entre os pares e o reconhecimento de suas ações. O homem representado na renascença é o estereótipo da virilidade, musculoso, barbudo, sério e com foco na pintura exagerada da braguilha.

É possível de verificar essa questão a partir das representações dos homens no século XVI e XVII. Esse 
homem é quase sempre representado em pé e de corpo todo. Essa performatividade nas pinturas é marcada pelo binarismo de gênero, a razão do homem e a emoção nas representações femininas.

Nas fotos em família o homem é representado sempre à direita, segundo Laneyrie-Dagen (2013: 456) este lado era o 'preferido de Deus'; a mulher sempre representada à esquerda, mais baixa, mesmo sendo mais alta, com os olhos voltados ao chão e por fim mais afastada do homem.

Retornando às diferenças e aos contextos da masculinidade na sociedade europeia, pois é dessa visão que os autores partem e narram a virilidade hegemônica, curiosa é a explicação da medicina da época, que dizia que os homens têm seu órgão exteriorizado em razão do calor, enquanto que o da mulher é interno pela falta deste calor. O livro trabalha em todos os capítulos com esse binarismo do órgão sexual: masculino e feminino. O que torna a leitura interessante é que todos os autores, cada um em seus respectivos capítulos, trabalham com o antônimo da virilidade: a feminilidade ou, pior ainda, o homem afeminado. Os argumentos são mais ricos (e mais toscos) do que é possível registrar nesta resenha. A título de exemplo, retiramos de uma obra de Ambroise Paré, do século XVI, o seguinte argumento: "Nunca encontramos, na história real, que algum homem tenha se transformado em mulher, já que a natureza sempre busca o mais perfeito, não o contrário, isto é, tornar o perfeito imperfeito (MANDRESSI: 290)".

Os autores relatam que a virilidade é oposto do mundo feminino, por isso, o homem que fugisse à regra seria o exemplo estereotipado da sociedade, algo que ainda é encontrado em nossas sociedades ocidentais. Não que o exemplo de homem viril fosse o mais cotado ou tinha mais amantes, mas, também obviamente, o que soubesse manter a distância das mulheres e do mundo feminino. $\mathrm{O}$ padre, por exemplo, era um homem viril, pois conseguia manter-se longe do feminino e das mulheres.

Diferentemente, mas nem tanto, das virilidades absolutas e da nobreza, o capítulo de Arlette Farge nos brinda com as virilidades populares dos séculos XVI, XVII e XVIII. A virilidade, além de ser do homem, era apreendida. Farge mostra a virilidade como herança da Europa pré-capitalista, portanto, poderíamos dizer, de uma virilidade pedagógica, que se aprende com os outros. O pai é o principal pedagogo dos jovens plebeus, mas Farge também mostra que não apenas ele, mas também a mulher. Nas classes populares, os jovens rapazes não abastados desenvolviam uma sexualidade prematura. Daí serem os casos com as jovens, consentidos ou não consentidos, um preâmbulo do que Bourdieu (2012) mais tarde denominaria de dominação masculina sobre a mulher pobre. A se destacar, nesse sentido, a virilidade e a violência como algo indissociável do homem para a sociedade e para a própria mulher. O homem e a mulher do Antigo Regime sofrem, em meio às transformações urbanas europeias, todas as formas de violência. Embora umas e outros sejam dominados, o homem precisa dominar a mulher para si e para os outros, pois nada é mais constrangedor do que um homem traído, sexualmente impotente e domado pela mulher.

Constituindo a virilidade o tema principal do livro, os autores procuram tratar de todos os seus aspectos na vida social do homem. Elizabeth Belmass mostra que a virilidade é um jogo, muitas vezes divertido. $\mathrm{O}$ vencedor tinha sua virilidade e força demarcadas, tanto nos jogos dos nobres, quanto nos populares, como o ainda embrionário futebol, o antepassado do rugby, no qual força e suor eram/são sinônimos de virilidade.

Não apenas de brutalidade e sangue se nutria a virilidade do Antigo Regime, mas também de sensibilidade e delicadeza, embora viris, em jogos como os de peteca, esgrima, além dos que mostravam os reflexos da nobreza, com o advento das armas de fogo, em caçar gansos e patos selvagens.

Por ser uma virilidade encenada, Michel Delon nos brinda com um capítulo sobre a ficção do homem e de sua virilidade nas artes, mais notadamente no teatro e na literatura. Essa virilidade paira sobre o imaginário de três figuras: o pai, como o ser triunfante e a virilidade dominadora; o jovem, em uma virilidade romanceada e, por fim, o fantasma de todo o homem, o eunuco.

Finalmente, não em ordem, mas por questões provocativas, como todo o texto, a virilidade no 'Novo Mundo'. Essa, porém, provavelmente pelas dificuldades de fontes, deixa brechas e interrogações sobre virilidades em contextos fora dos de matriz europeia, hegemônica. Ainda assim, a respeito dos que Vigarello denominou de selvagens, a virilidade nas Américas é instigante. Neste capítulo, o autor trata de questões que aprendemos na escola nos primeiros anos, a alteridade, no sentido de homem europeu como sinônimo de homem perfeito, em 
contraponto ao selvagem. Essa imagem, porém, mudará ao longo do texto, pois Vigarello reconhece que o homem selvagem deixou de ser o feio, o monstruoso, o imperfeito, para se tornar o belo, o virtuoso. Valendo-se de relatos de viajantes do séc. XVIII, admite a mudança em discursos e representações, pois, ao retratarem o selvagem, não podem não reconhecer sua liberdade, seu vigor e destemor, contrariando o modelo de Rousseau de homem civilizado "fraco e medroso".

Georges Vigarello, organizador, assim como todos os demais autores, neste primeiro volume de alguma forma trabalham o tema virilidade. $\mathrm{O}$ que surpreende, na imersão investigativa e histórica a que os autores levam o leitor sobre um assunto pouco tratado na historiografia, é a origem dessa historiografia, europeia. O tema é estudado sob inúmeros aspectos, inclusive os mais singelos, como gestos, ações ou expressões que manifestem, ainda que simbolicamente, o poder e a dominação que se perpetuam ainda hoje, século XXI.

As questões teóricas pouco abordadas sobre o tema instigam e provocam pesquisadoras/res da área sobre a necessidade de continuar a estudar um assunto imprescindível aos debates atuais no cenário acadêmico e de militância, mais notadamente os que envolvem estudos LGBT e as teorias de gênero e feministas. O livro trata de um tema extremamente atual na sociedade contemporânea, pois novas formas de masculinidade têm emergido na sociedade.

A utilidade da leitura é oferecer uma base histórica e permitir verificar até que ponto se pode falar em novas virilidades/masculinidades ou simplesmente em reinvenções que se fazem hegemônicas através dos tempos. Para os estudiosos, a análise mostra a persistência de velhas virilidades hegemônicas sob a aparência de novas masculinidades, camufladas em propagandas e personagens midiáticos, ou da política, mas modelos sempre perversamente opressores como sempre foram. Escreve Vigarello na introdução: “É um modelo que atravessa o tempo".

\section{Referências}

BOURDIEU, Pierre (2012). A dominação masculina. $11^{\circ}$ ed. Rio de Janeiro. Tradução Maria Helena. Bertrand Brasil.
BUTLER, Judith (2003). Problemas de gênero: feminismo e subversão da identidade. Rio de Janeiro: Civilização Brasileira.

KRISTZMAN, Lawrence D. (2013). A virilidade e seus "outros": a representação da masculinidade paradoxal. In: VIGARELLO, Georges. (Org.). História da virilidade: A invenção da virilidade, da antiguidade às luzes. Petrópolis, RJ: Vozes.

LANEYRIE-DAGEN, Nadeije (2013). O testemunho da pintura. In: VIGARELLO, Georges. (Org.). História da virilidade: A invenção da virilidade, da antiguidade às luzes. Petrópolis, RJ: Vozes.

MANDRESSI, Rafael (2013). O calor dos homens - Virilidade e pensamento médico na Europa. In: VIGARELLO, Georges. (Org.). História da virilidade: $A$ invenção da virilidade, da antiguidade às luzes. Petrópolis, RJ: Vozes.

Recebido em: 14/05/2017.

Aceito: 18/06/2017. 